\title{
Purinergic Signaling in the Pathophysiology and Treatment of Huntington's Disease
}

\author{
Melissa Talita Wiprich ${ }^{1,2}$ and Carla Denise Bonan 1,2,3* \\ ${ }^{1}$ Programa de Pós-Graduação em Medicina e Ciências da Saúde, Escola de Medicina, Pontifícia Universidade Católica do \\ Rio Grande do Sul, Porto Alegre, Brazil, ${ }^{2}$ Laboratório de Neuroquímica e Psicofarmacologia, Escola de Ciências da Saúde e \\ da Vida, Pontifícia Universidade Católica do Rio Grande do Sul, Porto Alegre, Brazil, ${ }^{3}$ Instituto Nacional de Ciência e \\ Tecnologia em Doenças Cerebrais, Excitotoxicidade e Neuroproteção, Porto Alegre, Brazil
}

\section{OPEN ACCESS}

Edited by:

Francisney Pinto Nascimento, Universidade Federal da Integração Latino-Americana, Brazil

Reviewed by:

Peter McCormick,

Queen Mary University of London,

United Kingdom

Hyung Nam,

Louisiana State University Health

Shreveport, United States

Adair Roberto Soares Santos, Federal University of Santa Catarina,

Brazil

*Correspondence:

Carla Denise Bonan

cbonan@pucrs.br;

carladbonan@gmail.com

Specialty section:

This article was submitted to

Neuropharmacology,

a section of the journal

Frontiers in Neuroscience

Received: 22 January 2021

Accepted: 04 June 2021

Published: 01 July 2021

Citation:

Wiprich MT and Bonan CD (2021)

Purinergic Signaling

in the Pathophysiology and Treatment

of Huntington's Disease.

Front. Neurosci. 15:657338.

doi: 10.3389/fnins.2021.657338
Huntington's disease $(H D)$ is a devastating, progressive, and fatal neurodegenerative disorder inherited in an autosomal dominant manner. This condition is characterized by motor dysfunction (chorea in the early stage, followed by bradykinesia, dystonia, and motor incoordination in the late stage), psychiatric disturbance, and cognitive decline. The neuropathological hallmark of HD is the pronounced neuronal loss in the striatum (caudate nucleus and putamen). The striatum is related to the movement control, flexibility, motivation, and learning and the purinergic signaling has an important role in the control of these events. Purinergic signaling involves the actions of purine nucleotides and nucleosides through the activation of P2 and P1 receptors, respectively. Extracellular nucleotide and nucleoside-metabolizing enzymes control the levels of these messengers, modulating the purinergic signaling. The striatum has a high expression of adenosine $A_{2 A}$ receptors, which are involved in the neurodegeneration observed in $\mathrm{HD}$. The P2X7 and P2Y2 receptors may also play a role in the pathophysiology of HD. Interestingly, nucleotide and nucleoside levels may be altered in HD animal models and humans with HD. This review presents several studies describing the relationship between purinergic signaling and $\mathrm{HD}$, as well as the use of purinoceptors as pharmacological targets and biomarkers for this neurodegenerative disorder.

Keywords: Huntington's disease, motor dysfunction, $\mathrm{A}_{2} \mathrm{~A}$ receptors, adenosine, ATP, nucleotide metabolism

\section{INTRODUCTION}

Huntington's disease (HD) is a devastating, progressive, and fatal neurodegenerative disorder inherited in an autosomal dominant manner (Smith-Dijak et al., 2019; Blumenstock and Dudanova, 2020). It is triggered by an expansion of a cytosine-adenine-guanine (CAG) triplet repeat in exon 1 of the huntingtin (HTT) gene, located on chromosome 4 (The Huntington's Disease Collaborative Research Group, 1993; Capiluppi et al., 2020). This change leads to an expanded polyglutamine (polyQ) region in the encoded HTT protein (Bailus et al., 2017; Rai et al., 2019). As a result, the expressed HTT protein is a mutant (mHTT; Cybulska et al., 2020). Individuals with up to $35 \mathrm{CAG}$ repeats are usually considered healthy, while people with 36 to 39 CAG repeats may or may not develop the signs and symptoms of HD (Shoulson and Young, 2011; Capiluppi et al., 2020). More than 50 CAG repeats always cause the disease (Capiluppi et al., 2020). There is an inverse correlation 
between the number of CAG repeats, age at onset, and the severity of HD symptoms (Bates et al., 2015; Petersén and Weydt, 2019).

It is estimated that the mean $\mathrm{HD}$ prevalence is 5 in 100,000 people (Baig et al., 2016; Illarioshkin et al., 2018). $\mathrm{HD}$ is characterized by a neurobehavioral progressive triad with motor dysfunction, psychiatric disturbance, and cognitive decline (Stahl and Feigin, 2020). The motor dysfunction is subdivided into two stages: In the early stage, there are abnormal involuntary movements, known as chorea, while in the late stage, the voluntary movements are impaired, causing bradykinesia, dystonia, and motor incoordination. The observed neuropsychiatric symptoms include depression, apathy, irritability, anxiety, and psychosis. The cognitive impairment often precedes the motor abnormalities. The cognitive alterations include impaired attention and visuospatial functions and slow planning processing speed. The cognitive decline progresses to dementia (Stahl and Feigin, 2020), and death becomes imminent 15-20 years after disease onset (Blumenstock and Dudanova, 2020). These dysfunctions can be attributed to multiple brain regions that exhibit neurodegeneration, including the cerebral cortex, thalamus, subthalamic nucleus, globus pallidus, substantia nigra, and hypothalamus. However, the hallmark of the disease is the pronounced neuronal loss in the striatum (caudate nucleus and putamen; Rubinsztein, 2002; Ramaswamy et al., 2007; Coppen and Roos, 2017). Furthermore, HD patients may develop metabolic symptoms including weight loss and cardiac and musculoskeletal dysfunction, among others (Blum et al., 2018; Croce and Yamamoto, 2019; Dufour and McBride, 2019).

The striatum is a region responsible for the control of many behaviors, such as movement, flexibility behavior, motivation, and learning (Koch and Raymond, 2019). Two different striatal pathways express distinct neurotransmitters and neuropeptides (Graybiel, 2000). The indirect pathway contains cholinergic interneurons that express dopamine $D_{2}$ receptors $\left(D_{2} R\right)$, adenosine $A_{2 A}$ receptors $\left(A_{2 A} R\right)$, and enkephalin; it projects to the globus pallidus external (Figure 1; GPe; Albin et al., 1989). This pathway acts by inhibiting voluntary movements; because the neurons are degenerated in the early stage of $\mathrm{HD}$, there is a decrease in $\mathrm{D}_{2} \mathrm{R}$ and $\mathrm{A}_{2 A} \mathrm{R}$ and thus uncontrolled voluntary movements, coinciding with chorea symptoms (Figure 1; Albin et al., 1989; Graybiel, 2000; Koch and Raymond, 2019). The direct pathway expresses spiny projection neurons (SPNs) that contain gamma-aminobutyric acid (GABA) coexisting with neuropeptide $\mathrm{P}$ and dynorphin. Besides, dopamine $\mathrm{D}_{1}$ receptors $\left(D_{1} R\right)$ project into the substantia nigra pars reticulate (SNpr) and globus pallidus internal (GPi), initiating voluntary movements (Figure 1; Albin et al., 1989). In the late stage of HD, besides the damaged indirect pathway, there is the degeneration of direct pathway neurons, a phenomenon that decreases $\mathrm{D}_{1} \mathrm{R}$ and cortex stimulation. This phenomenon leads to the hypokinetic symptoms, which are typical of this stage (Figure 1; Albin et al., 1989; Graybiel, 2000; Koch and Raymond, 2019).

Furthermore, neurotransmitters, such as dopamine, acetylcholine, glutamate, and GABA, are involved in motor coordination and alterations in their levels induce motor deficits.
Evidence has demonstrated alterations in these neurotransmitter levels in early- and late-stage HD (Spokes, 1980; Kish et al., 1987; Jamwal et al., 2015; Jamwal and Kumar, 2019). These changes in neurotransmitter levels might cause important intracellular biochemical changes, such as a decrease in mitochondrial complex II, III, and IV activity and adenosine triphosphate (ATP) levels, calcium $\left(\mathrm{Ca}^{2+}\right)$ overload, excitotoxicity, oxidative stress, and mitochondrial dysfunction (Johri et al., 2013; Carmo et al., 2018; Jodeiri Farshbaf and Kiani-Esfahani, 2018), triggering cell death (Liot et al., 2017). Thus, there is an imbalance in the activity between the direct and indirect pathways, resulting in an inadequate functioning of different neurotransmitter systems in $\mathrm{HD}$. One of the neurotransmitter systems involved in the pathophysiology of $\mathrm{HD}$ is the purinergic signaling (Burnstock, 2015), mediated by the action of nucleotides and nucleosides in the $\mathrm{P} 2$ and $\mathrm{P} 1$ receptors, respectively. Both ATP and adenosine are the most important messengers in the purinergic system, which participates in the control of several behaviors (Burnstock, 2015). Adenosine acts as a neuromodulator; specifically, it modulates dopaminergic and glutamatergic neurotransmission systems (Ferré et al., 2007; Fuxe et al., 2007; Ciruela et al., 2015). Changes in ATP and adenosine levels have been observed in HD (Seong et al., 2005; Kao et al., 2017). Studies have focused on the impact of purinergic signaling on $\mathrm{HD}$ as well as the development of pharmacological strategies related to the purinergic system as therapies for HD (Blum et al., 2002; Chou et al., 2005; Simonin et al., 2013; Villar-Menéndez et al., 2013; Kao et al., 2017). Therefore, this review will discuss the role of purinergic signaling in HD as well as the involvement of purinoceptors in the disease progression and their relevance for application as pharmacological targets and biomarkers for HD.

\section{PURINERGIC SIGNALING}

Adenosine triphosphate and adenosine are recognized as the most powerful purinergic signaling messengers (Burnstock, 1972). Purinergic receptors are classified into P1 and P2 according to their biochemical and pharmacological properties (Burnstock, 2018; Cheffer et al., 2018). P2 receptors are activated by purines [ATP, adenosine diphosphate (ADP)] and pyrimidines (uridine triphosphate, uridine diphosphate) and classified as $\mathrm{P} 2 \mathrm{X}$ and $\mathrm{P} 2 \mathrm{Y}$ receptors (Abbracchio and Burnstock, 1994; Burnstock, 2011). P2X receptors are ATPgated ion channels permeable to sodium $\left(\mathrm{Na}^{+}\right)$and $\mathrm{Ca}^{2+}$ influx and potassium $\left(\mathrm{K}^{+}\right)$efflux, which leads to depolarization of the cell membrane. Seven subunits of these receptors (P2X1-7) are expressed by different cells (Burnstock, 2008). $\mathrm{P} 2 \mathrm{Y}$ receptors are metabotropic, activated by purines and pyrimidines, and subdivided into eight receptor subtypes $\left(\mathrm{P}_{1} \mathrm{Y}_{1}, \mathrm{P}_{2} \mathrm{Y}_{2}, \mathrm{P} 2 \mathrm{Y} 4, \mathrm{P} 2 \mathrm{Y}_{6}, \mathrm{P}_{11}, \mathrm{P}_{12}, \mathrm{P}_{13} \mathrm{Y}_{13}\right.$, and $\mathrm{P} 2 \mathrm{Y}_{14}$; Burnstock, 2008; Puchałowicz et al., 2014). P1 receptors are metabotropic, selective for adenosine, and exert physiological actions through four subtypes named $A_{1}\left(A_{1} R\right), A_{2 A}\left(A_{2 A} R\right)$, $A_{2 B}\left(A_{2 B} R\right)$, and $A_{3}\left(A_{3} R\right)$ (Fredholm et al., 2001; Burnstock, 2018; Ciruela, 2020). Low adenosine levels activate $A_{1} R$ and $A_{3} R$ receptors, whereas high adenosine levels activate $A_{2 A} R$ 


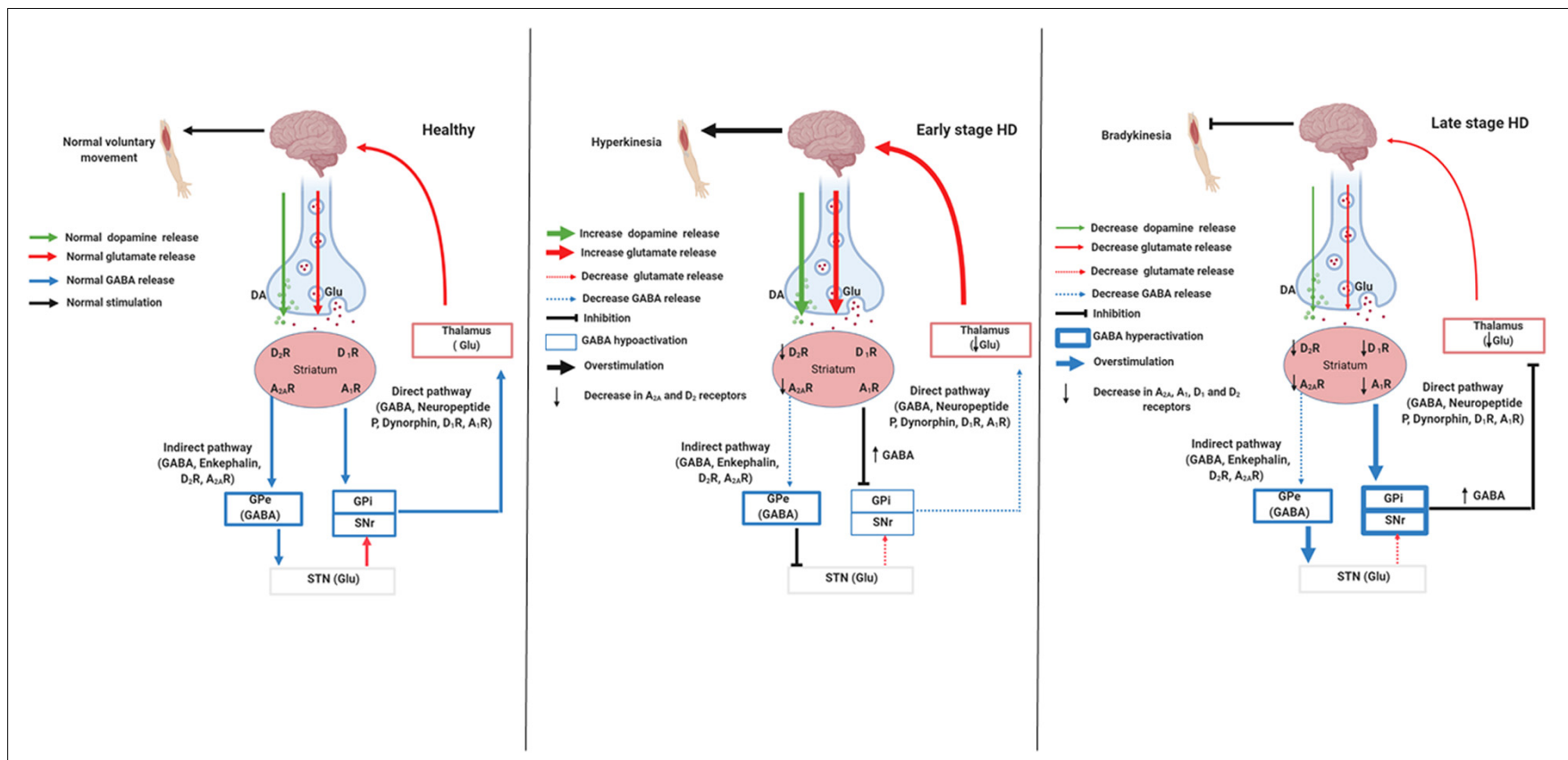

FIGURE 1 | Signaling pathways involved in stages of Huntington's disease. Created with Biorender.com.

and $A_{2 B} R$ receptors (Borea et al., 2018). $A_{1} R$ and $A_{3} R$ activate $\mathrm{G}_{i / o}$ protein, inhibiting the production of cyclic adenosine monophosphate (cAMP), adenylate cyclase (AC), protein kinase A (PKA), and, consequently, GABA uptake. On the other hand, $\mathrm{A}_{2 A} \mathrm{R}$ is activated through $\mathrm{Gs}$ protein that stimulates cAMP production, activating $\mathrm{AC}$ and $\mathrm{PKA}$, increasing GABA uptake. In addition, $\mathrm{A}_{2 B} \mathrm{R}$ also act through Gs protein (Sheth et al., 2014; Borea et al., 2018).

Nucleotide levels are regulated by ectonucleotidases, a group of enzymes constituted by nucleotide pyrophosphatases/phosphodiesterases (NPPs), nucleoside triphosphate diphosphohydrolases (NTPDases; CD39), alkaline phosphatase, and ecto- $5^{\prime}$-nucleotidase $\left(5^{\prime}-\mathrm{NT}, \mathrm{CD} 73\right.$; Bonan, 2012; Zimmermann, 2021). Ectonucleotidases promote the extracellular hydrolysis of ATP, producing ADP, adenosine monophosphate (AMP), and adenosine controlling their extracellular concentrations (Burnstock, 1980; Bonan, 2012; Cheffer et al., 2018; Cieslak et al., 2019).

Adenosine, through the action of adenosine deaminase (ADA), can be subsequently deaminated to inosine (Latini and Pedata, 2001). Inosine is phosphorylated by purine nucleoside phosphorylase (PNP) into hypoxanthine and then degraded to the stable end product uric acid (Yegutkin, 2008; Ribeiro et al., 2016). Adenosine levels are also regulated by unidirectional and bidirectional transporters, which allow nucleosides to move between the intracellular and extracellular compartments (Fredholm et al., 2001; Ribeiro et al., 2016; Stockwell et al., 2017). Finally, the action of nucleosides is then limited either through their conversion to other products of purine catabolism or through re-synthesis into nucleotides (Ribeiro et al., 2016).

\section{THE ROLE OF P1 RECEPTORS IN HUNTINGTON'S DISEASE}

As mentioned above, adenosine mediates its effect through four adenosine receptors $\left(A_{1}, A_{2 A}, A_{2 B}\right.$, and $\left.A_{3}\right) . A_{1} R$ and $A_{2 A} R$ are mainly involved in the central effects of adenosine (Ciruela et al., 2015). $A_{1} R$ is the most abundant receptor in the brain-widely expressed in the hippocampus, cerebellum, thalamus, brain stem, and spinal cord-whereas $\mathrm{A}_{2 A} \mathrm{R}$ is concentrated abundantly in the striatum (Burnstock, 2008; Borea et al., 2018).

It is known that $A_{1} R$ can interact with $D_{1} R$ to form heterodimers. Pre-synaptic $\mathrm{A}_{1} \mathrm{R}$ activation causes depression of excitatory transmission through $\mathrm{Ca}^{2+}$ channel inhibition and neuronal hyperpolarization by regulation of potassium channel. This action leads to a reduction in the release of many neurotransmitters, including acetylcholine, glutamate, dopamine, noradrenaline, and serotonin; this reduction may be beneficial in some central nervous system diseases (Yoon and Rothman, 1991; Von Lubitz et al., 1994; Gundlfinger et al., 2007).

$\mathrm{A}_{2 \mathrm{~A}}$ receptors can co-localize with $\mathrm{D}_{2} \mathrm{R}$, resulting in $\mathrm{A}_{2 A} \mathrm{R} / \mathrm{D}_{2} \mathrm{R}$ heteromers, which have a crucial role in the modulation of motor function. Thus, $\mathrm{A}_{2 A} \mathrm{R}$ activation decreases the affinity and function of $\mathrm{D}_{2} \mathrm{R}$ for agonist or antagonist drugs (Borea et al., 2018). In addition, $\mathrm{A}_{2 A} \mathrm{R}$ plays an important role in facilitating glutamate release, potentiating their effects via $N$-methyl-D-aspartate (NMDA) receptors as well as other neurotransmitters, such as GABA, glycine, acetylcholine, noradrenaline, and serotonin (Cunha, 2005; León-Navarro et al., 2018). In addition, there is functional cooperation between $\mathrm{A}_{2 A} \mathrm{R}$ and $\mathrm{A}_{1} \mathrm{R}$ (heteromers), leading to antagonist actions on dopamine release-that is, when $A_{1} R$ is 
stimulated it inhibits dopamine release, which would oppose the stimulating effects of $\mathrm{A}_{2 A} \mathrm{R}$ through action on striatal $\mathrm{D}_{2} \mathrm{R}$ (León-Navarro et al., 2018). $\mathrm{A}_{2 A} \mathrm{R}$ can also form heterodimers with glutamate receptors (metabotropic 5 subtype [mGlu5]). The $\mathrm{A}_{2 A} \mathrm{R} / \mathrm{mGlu} 5$ heterodimers exert a synergistic inhibitory effect on dopamine binding to $\mathrm{D}_{2} \mathrm{R}$ (León-Navarro et al., 2018). Together, these findings lead to the hypothesis that dysfunction in adenosine receptors may cause an imbalance between dopaminergic, glutamatergic, and GABAergic neurotransmission systems, which would explain pathological processes underlying HD. This hypothesis is supported by several studies that focus on adenosine receptors, mainly $\mathrm{A}_{2 A} \mathrm{R}$, and to a lesser extent $\mathrm{A}_{1} \mathrm{R}$. Here we described the involvement of $A_{1} R$ and $A_{2 A} R$ in the progression of HD.

\section{$A_{1} R$ in Huntington's Disease}

The first study investigating the involvement of $\mathrm{P} 1$ receptors in $\mathrm{HD}$ was focused on the analysis of the $\mathrm{A}_{1} \mathrm{R}$ subtype in the striatum and parietal-frontal culture of post-mortem cerebral samples from $H D$ subjects. Using a selective $A_{1} R$ agonist[3N] (N6-cyclohexyl)-adenosine-the authors demonstrated a $60 \%$ decrease in $A_{1} R$ with an increase in the affinity of the binding drug for the receptor in the striatum (Whitehouse et al., 1985). Later, Matusch et al. (2014) quantified, through position emission tomography (PET) imaging, the cerebral binding of $A_{1} R$ in $H D$ subjects subdivided into four groups: pre-manifest individuals far from (pre-HD-A) or pre-manifest individuals near (pre-HD-B) the predicted symptom onset, manifest HD patients, and controls. The results demonstrated a decrease in caudate and putaminal volumes from pre-HD and HD patients compared with control, more $\mathrm{A}_{1} \mathrm{R}$ in the thalamus of pre-HD-A individuals compared with control, and less $\mathrm{A}_{1} \mathrm{R}$ in caudate and amygdala in all stages of the disease. There was also a strong direct correlation between $A_{1} R$ with the years since disease onset-that is, the more advanced the disease, the larger the loss of $A_{1} R$ (Matusch et al., 2014). This finding indicates that $A_{1} R$ is involved in the pathogenesis of HD and might be a biomarker in specific brain areas for HD progression.

To shed further light on the possible role of $A_{1} R$ in $\mathrm{HD}$, pharmacological and genetic mouse models have been used to understand the functionality of these receptors. In a pharmacological model of HD induced by 3-nitropropionic acid (3-NPA)-the main toxin used to induce an HD-like phenotype in an animal model through mitochondrial inhibition-the acute (two or three injections) and chronic (8 days) treatment with $\mathrm{A}_{1} \mathrm{R}$ agonist adenosine amine congener (ADAC) provoked different behavioral and neurochemical responses in mice (Blum et al., 2002). In the study, animals that received two injections of ADAC were called $\mathrm{ADAC}_{4 / 5}$, whereas animals that received three injections were called $\mathrm{ADAC}_{3 / 5} . \mathrm{ADAC}_{4 / 5}$ and $\mathrm{ADAC}_{3 / 5}$ treatment attenuated dystonia of hindlimbs caused by 3-NPA, while the $\mathrm{ADAC}_{4 / 5}$ group showed increased striatal succinate dehydrogenase (SDH) activity inhibited by 3-NPA and a reduced striatal lesion volume (Blum et al., 2002). Chronic ADAC treatment did not alter the motor symptoms or striatal lesion size, and there was no increase in the SDH activity (Blum et al., 2002). Interestingly, chronic treatment dramatically decreased the $\mathrm{A}_{1} \mathrm{R}$ density in the striatum and cortex, whereas acute treatment did not modify the $A_{1} R$ density (Blum et al., 2002).

Consistently, in R6/2 mice-the most widely used transgenic model of $\mathrm{HD}-\mathrm{A}_{1} \mathrm{R}$ was significantly reduced in the cortex and striatum compared with the wild type (WT) group (Ferrante et al., 2014). Moreover, corticostriatal slices of R6/2 treated with the selective $A_{1} R$ agonist cyclopentyladenosine (CPA) showed a marked reduction in synaptic transmission, with consequent inhibition of glutamate release in the pre-synaptic terminal (Ferrante et al., 2014). On the contrary, in a pharmacological model of HD induced by malonate, Alfinito et al. (2003) observed that intraperitoneal and intrastriatal $A_{1} R$ blockade with the $A_{1} R$ antagonist CPX potentiated the effect of malonate, reducing striatal dopamine levels, tyrosine hydroxylase $(\mathrm{TH})$ content, and GABA levels as well as GABAergic and dopaminergic neuronal loss (Alfinito et al., 2003). Together, these findings lead to the hypothesis that the pharmacological therapy with $A_{1} R$ agonists may be a beneficial protective treatment in the early stage of $\mathrm{HD}$ (Figure 2). However, $A_{1} R$ antagonist drugs did not seem to be an alternative for the treatment of $\mathrm{HD}$ due to the crosstalk with GABAergic neurons, which enhanced the susceptibility to toxic insults, reducing $A_{1} R$ in these two populations of neurons.

\section{$A_{2 A} R$ Alterations in Huntington's Disease Progression \\ $A_{2 A} R$ : Focus on Human Studies}

Contrary to $\mathrm{A}_{1} \mathrm{R}$, the role of $\mathrm{A}_{2 A} \mathrm{R}$ in $\mathrm{HD}$ has been more widely investigated in human and animal models. The first evidence for the involvement of $\mathrm{A}_{2 A} \mathrm{R}$ in $\mathrm{HD}$ was provided by autoradiographic mapping using the selective $A_{2 A} \mathrm{R}$ agonist ligand CGS 21680 in brain sections from $\mathrm{HD}$ patients and controls without the pathology. The results showed a dramatic decrease in $\mathrm{A}_{2 A} \mathrm{R}$ in the caudate nucleus, putamen, nucleus accumbens, olfactory tubercle, and globus pallidus lateral in HD compared with control samples (Martinez-Mir et al., 1991). In a subsequent study, analyses of post-mortem neuronal tissue in HD subjects in the early, intermediate, and late stages of the disease showed $\mathrm{A}_{2 A} \mathrm{R}$ bound the selective $\mathrm{A}_{2 A} \mathrm{R}$ agonist ligand CGS 21680 within the caudate nucleus and putamen of the control brain. In the early and intermediate stages of $\mathrm{HD}$, there was a dramatic loss of $\mathrm{A}_{2 A} \mathrm{R}$ binding, whereas in brain tissue with the late stage of the disease there was no detectable $A_{2 A} \mathrm{R}$ binding (Glass et al., 2000).

On the other hand, higher $\mathrm{A}_{2 A} \mathrm{R}$ levels are detected in peripheral blood cells, such as platelets, lymphocytes, and neutrophils at pre-symptomatic, early, and late stages of HD patients (Varani et al., 2003; Maglione et al., 2005). In addition, the higher $\mathrm{A}_{2 A} \mathrm{R}$ levels in platelets correlated with CAG expansion and with anticipation in years since the onset of symptoms (Maglione et al., 2005, 2006). Thus, these findings indicate that there are $\mathrm{A}_{2 A} \mathrm{R}$ alterations in the peripheral and central nervous systems in $\mathrm{HD}$ patients, and $\mathrm{A}_{2 A} \mathrm{R}$ in blood cells might be an easy biomarker to detect and monitor HD progression.

Genetic studies support the relationship between $\mathrm{A}_{2 A} \mathrm{R}$ and HD pathology. Two similar cohort studies performed in France 


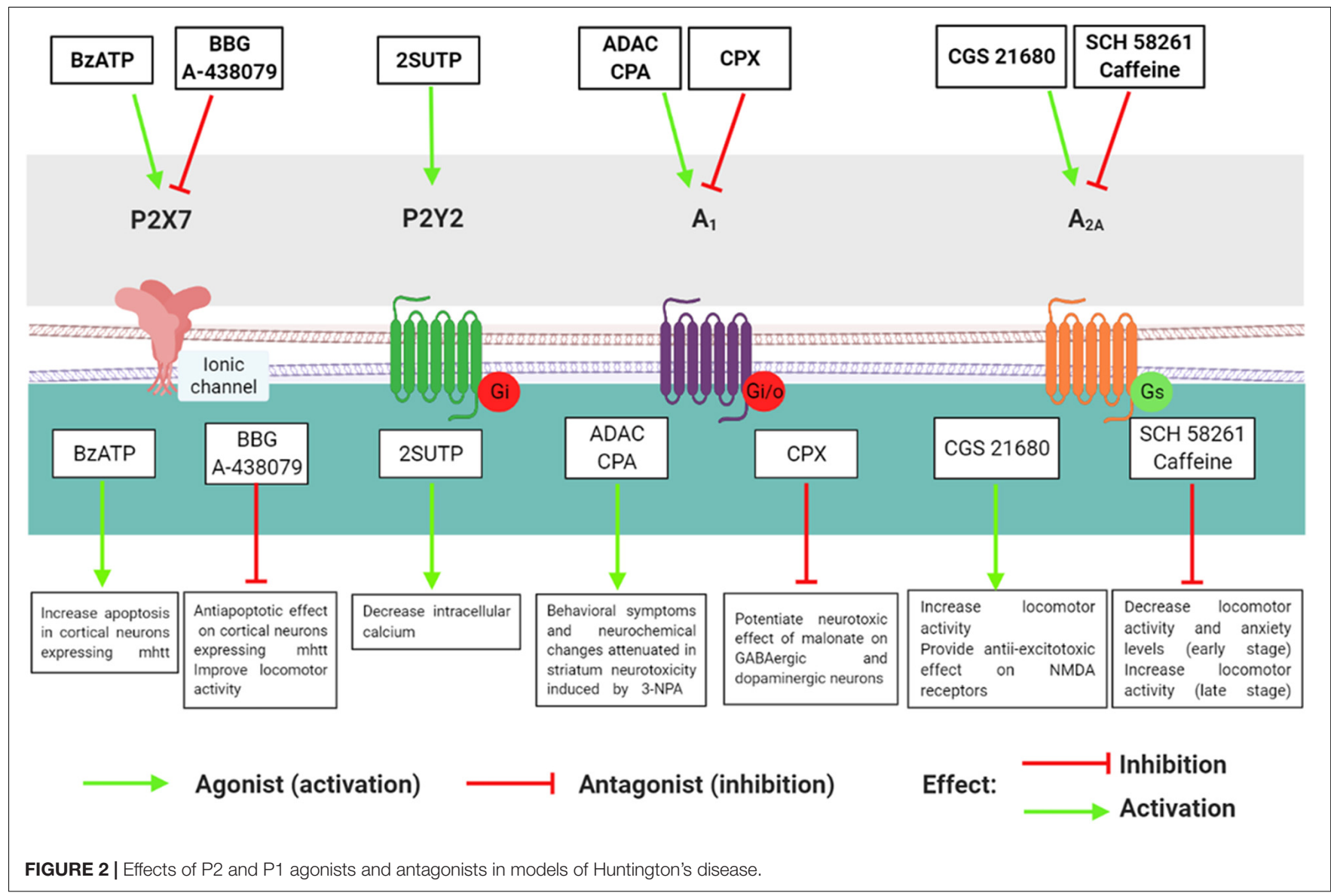

and Germany with HD subjects showed gene polymorphisms in the $\mathrm{A}_{2 A} R$ gene (ADORA2A), mainly the rs5751876 variant, which was associated with a variation in the age at onset on the disease (Dhaenens et al., 2009; Taherzadeh-Fard et al., 2010). Compelling evidence showed increased methylcytosine and decreased 5-methylhydroxylation (enzymes responsible by DNA methylation) in the $5^{\prime}$ untranslated region (UTR) of ADORA2A in the putamen of HD patients compared with their respective controls (Villar-Menéndez et al., 2013). These data suggest that a dysfunction in $\mathrm{A}_{2 A} \mathrm{R}$ gene expression might also contribute to the pathophysiology of HD.

Some habitually consumed drinks and foods-such as coffee, tea, chocolate, and soda-contain caffeine, a non-selective $A_{1} R$ and $A_{2 A} R$ antagonist (Chen and Chern, 2011). Supported by the evidence that adenosine receptor antagonists could exert beneficial effects in neurodegenerative diseases, Simonin et al. (2013) raised the hypothesis that caffeine may be a lifestyle modifier in HD. For this reason, a retrospective study evaluated a possible relationship between caffeine consumption and age at onset in 80 subjects with HD. The data showed $>190 \mathrm{mg} /$ day caffeine consumption was significantly associated with an earlier age at onset of the disease (Simonin et al., 2013). This finding leads to the hypothesis that this association may not be a relationship with food habits but might be related to genetic determinants, such as ADORA2A or
CYP1A genes, that may cause an earlier age at onset of the disease, influence a higher caffeine intake, and modulate behavioral effects.

\section{$A_{2 A} R$ : Evidence in Animal Models}

Changes in $\mathrm{A}_{2 A} \mathrm{R}$ gene expression and density have been found in transgenic animal models of HD. R6/2, HD100, and tgHD mice at 4 weeks to 24 months of age had a decrease in $\mathrm{A}_{2 A} \mathrm{R}$ levels and density (Cha et al., 1999; Chan et al., 2002; Bauer et al., 2005; Tarditi et al., 2006); R6/2 animals less than 3 weeks of age had an increase in $\mathrm{A}_{2 A} \mathrm{R}$ levels and density (Tarditi et al., 2006). In contrast, Benn et al. (2007) did not find alterations in $A_{2 A} R$ gene expression in the YAC128 genetic model of HD (Benn et al., 2007). These results suggest that alterations in gene expression $\mathrm{A}_{2 A} \mathrm{R}$ could have an association with HTT length and age of disease.

Several studies with controversial results have evaluated whether $\mathrm{A}_{2 A} \mathrm{R}$ genetic and pharmacological activation or blockade affects behavioral symptoms and/or striatal degeneration in genetic or pharmacological models of HD. $\mathrm{A}_{2 A} \mathrm{R}$ knockout between 12 and 21 weeks of age in the N171$82-\mathrm{Q}$ transgenic model of HD had a deleterious impact on survival, motor coordination, body weight, striatal volume, and enkephalin and neuropeptide messenger RNA (mRNA) levels 
(Mievis et al., 2011). On the other hand, $\mathrm{A}_{2 A} \mathrm{R}$ knockout in two R6/2 transgenic lines of HD (CAG120 and CAG240) did not cause working memory deficits and locomotor impairment compared with HD CAG120 and HD CAG240 WT mice (Li et al., 2015). Moreover, pharmacological blockade of $A_{2 A} R$ with $1 \mathrm{mg} / \mathrm{kg}$ of the antagonist KW60002 in R6/2 (CAG240) mice at 3 months of age also reversed the working memory deficits compared with R6/2 (CAG240) mice that did not receive KW60002 (Li et al., 2015). Consistent with that finding, Fink et al. (2004) reported that $\mathrm{A}_{2 A} \mathrm{R}$ genetic inactivation is beneficial to the HD animal model. The authors used two HD mouse models on different genetic backgrounds, namely C57BL/6 and 129-Steel; these models had $\mathrm{A}_{2 A} \mathrm{R}$ knockout (KO; $\mathrm{C} 57 \mathrm{BL} / 6-\mathrm{A}_{2 A}-\mathrm{KO}$ and 129-Steel- $\mathrm{A}_{2 A}-\mathrm{KO}$ ). C57BL/6- $\mathrm{A}_{2 \mathrm{~A}}-\mathrm{KO}$ mice and their respective WT mice at 6 months of age were administered 3-NPA twice daily for 5 days. C57BL/6-WT mice developed bradykinesia with dystonic movements and bilateral striatal lesion compared with C57BL/6- $\mathrm{A}_{2 A}-\mathrm{KO}$ mice (Fink et al., 2004). Furthermore, in the 129-Steel line, 3-NPA administration also resulted in bilateral striatal lesions in WT compared with $\mathrm{A}_{2 A} \mathrm{R} \mathrm{KO}$ (Fink et al., 2004).

More recently, Domenici et al. (2018) investigated in vivo and in vitro the effect of 3-NPA in a transgenic rat strain overexpressing $A_{2 A} R$. Surprisingly, there was a reduction in striatal lesion volume induced by 3-NPA in transgenic rats overexpressing $\mathrm{A}_{2 A} \mathrm{R}$ compared with WT animals. There was greater striatal cell viability in transgenic rats overexpressing $\mathrm{A}_{2 A} \mathrm{R}$ than WT rats after exposing corticostriatal slices to $10 \mathrm{mM}$ 3-NPA. In addition, 3-NPA treatment depressed synaptic transmission in corticostriatal slices of WT animals compared with rats overexpressing $A_{2 A} R$ (Domenici et al., 2018). These data lead to the idea that $A_{2 A} \mathrm{R}$ is an important target involved in the pathophysiology of $\mathrm{HD}$ and $\mathrm{A}_{2 A} \mathrm{R}$ modulation might be beneficial to attenuate the neurodegenerative progression of the disease.

$\mathrm{A}_{2 A}$ receptors modulation has demonstrated beneficial effects against neurodegeneration and HD-like behavioral symptoms induced by quinolinic acid and 3-NPA. The behavioral symptoms like hyperkinesia (increased locomotor activity) and the increase in anxiety levels persistent in early stage HD were decreased by blocking $A_{2 A} R$ using two $A_{2 A} R$ antagonists (SCH 58261 and caffeine; Popoli et al., 2002; Scattoni et al., 2007; Mishra and Kumar, 2014). In addition, the bradykinesia (decrease in locomotor activity) present in late stage of the disease was reverted with the use of $\mathrm{SCH}$ 58261 and caffeine (Mishra and Kumar, 2014; Bortolatto et al., 2017). Blocking $\mathrm{A}_{2 A} \mathrm{R}$ using $\mathrm{SCH} 58261$ and caffeine protected against the elevated glutamate extracellular levels, excessive stimulation of NMDA receptors, increased reactive oxygen species, oxidative stress, and mitochondrial dysfunction (Popoli et al., 2002; Mishra and Kumar, 2014; Bortolatto et al., 2017). Furthermore, Fink et al. (2004) showed that striatal neurotoxicity induced by 3-NPA in C57BL/6 mice resulted in bilateral striatal lesions, while mice pre-treated with the $\mathrm{A}_{2 \mathrm{~A}} \mathrm{R}$ antagonist caffeine before 3-NPA injections did not show striatal lesions.
$\mathrm{A}_{2 A}$ receptors pharmacological blockade also attenuated the levels of cyclooxygenase (COX-2), prostaglandin E2, and brain-derived neurotrophic factor, a member of the neurotrophin family that participates in synaptic transmission and regulates neuronal proliferation and survival (Minghetti et al., 2007; Potenza et al., 2007). In R6/2 mice, $A_{2 A} R$ blockade prevented alterations in anxious responses and abolished the increase in NMDA-receptor-induced striatal toxicity (Domenici et al., 2007). However, $A_{2 A} R$ antagonism had a potentially detrimental effect on neurotoxicity induced by quinolinic acid in an animal model of $\mathrm{HD}$; specifically, there was increased striatal glutamate outflow (Gianfriddo et al., 2003).

Considering that a pronounced loss of $\mathrm{A}_{2 A} \mathrm{R}$ occurs in $\mathrm{HD}$, researchers have tested whether $\mathrm{A}_{2 \mathrm{~A}}$ agonists could ameliorate HD symptoms. The selective $\mathrm{A}_{2 A} \mathrm{R}$ agonist CGS 21680 reverted the hypolocomotor profile and the increase in the ventricle/brain ratio in $\mathrm{R} 6 / 2$ mice (Chou et al., 2005). CGS 21680 also attenuated the NMDA toxic effects in corticostriatal slices (Martire et al., 2007) and reduced the expression of NMDA receptor subunits NR1 in the striatum of R6/2 and WT mice. In addition, there was a decrease in the NR2A/NR2B ratio in the striatum of WT mice, inducing a pro-excitotoxic effect, whereas the NR2A/NR2B ratio was increased in HD mice (R6/2), and thus the NMDA receptors provided an anti-excitotoxic effect (Ferrante et al., 2010). Finally, in the liver of R6/2 mice, CGS 21680 treatment also had a protective effect, suppressing mHTT aggregates and decreasing the levels of crucial transcription factor and protein chaperones (Hsp27 and Hsp70; Chiang et al., 2009). Taken together, it is possible to suggest that $A_{2 A} R$ alterations in $\mathrm{HD}$ occur in the central nervous system as well as other tissues. Thus, pharmacological modulation of $\mathrm{A}_{2 A} \mathrm{R}$ through agonist or antagonist administration might exert a neuroprotective effect against HD progression (Figure 2), considering the stage of the disease, drug dosage, and period of pharmacological administration.

\section{P2 RECEPTOR INVOLVEMENT IN HUNTINGTON'S DISEASE}

Contrary to P1 receptors, there are few studies about P2 receptors in $\mathrm{HD}$ and their roles in this neurodegenerative disease remain elusive. Díaz-Hernández et al. (2009) investigated $\mathrm{P} 2 \mathrm{X} 7$ receptor involvement in $\mathrm{HD}$ using two genetic mouse models of HD (Tet/HD94 and R6/1). First, cortical and striatal neurons showed an increase in P2X7 receptor protein and mRNA levels in Tet/HD94 and R6/1 compared with WT mice (Díaz-Hernández et al., 2009). Moreover, transgenic HD mice had higher P2X7 receptor levels in synaptosomes and were more sensitive to the P2X7 agonist BzATP than WT mice. This increase in sensitivity induced by BzATP led to apoptosis of cultured cortical neurons expressing mHTT, which was prevented by the P2X7 antagonist brilliant blue (BBG) (Díaz-Hernández et al., 2009). Due to the protective effect of BBG in neuronal culture, the authors investigated the efficacy 
of P2X7 antagonists BBG and A-438079 in R6/1 mice and their WT on body weight and locomotor parameters. BBG administration fully prevented body weight loss and significantly improved motor coordination and locomotor performance in R6/1 compared with WT mice. The antagonist A-438079 also prevented body weight loss and improved locomotor parameters in $\mathrm{R} 6 / 1$ mice, but the effect was only moderate (Díaz-Hernández et al., 2009). These data support the hypothesis that changes in P2X7 receptor levels and function lead to an increase in $\mathrm{Ca}^{2+}$ permeability; this eventuality could induce excitotoxicity and oxidative stress in neurons, changes that are related to $\mathrm{HD}$ pathogenesis (Figure 2). In the future, studies using $\mathrm{P} 2 \mathrm{X} 7$ receptor antagonists should be performed because these compounds may have therapeutic potential for HD treatment.

Martire et al. (2021) investigated the expression and the functioning of P2X7R in two genetic models of HD: ST14A rat striatal cells, expressing full-length wild-type (WT, Q15) or mutant (Q120) htt and R6/2 mice, which resembles to juvenile forms of HD. In the presence of HD mutation, there is an altered $\mathrm{P} 2 \mathrm{X} 7 \mathrm{R}$ expression and a larger $\mathrm{P} 2 \mathrm{X} 7 \mathrm{R}$ response to the agonist BzATP, inducing cell death and reducing synaptic transmission. BzATP effect observed in the electrophysiology experimental setting are dependent of $\mathrm{A}_{1} \mathrm{R}$ activation. These findings may permit a better understanding of the P2X7R mechanisms and evaluate the therapeutic potential of P2X7 antagonists in HD. Certainly, this topic requires a deepen investigation since recent studies demonstrated changes in P2X7R in the brain of HD subjects (Ollà et al., 2020). Ollà et al. (2020) observed that the protein levels of the full-length form of P2X7R, also called P2X7R-A, as well as the exclusively human naturally occurring variant lacking the $\mathrm{C}$-terminus region, named P2X7R-B, are upregulated. These augmented protein levels can be explained by elevated P2X7R mRNA levels. In addition, $\mathrm{P} 2 \mathrm{X} 7 \mathrm{R}$ introns 10 and 11 are more retained in HD subjects when compared with controls patients (Ollà et al., 2020). Therefore, further studies are required to evaluate the implications of $\mathrm{P} 2 \mathrm{X} 7 \mathrm{R}$ in $\mathrm{HD}$ and if this receptor may be a target for the development of new pharmacological therapies for this pathology.

Regarding to other P2 receptors, Glaser et al. (2020) analyzed whether $\mathrm{P}_{2} \mathrm{Y}_{2}$ receptors might be involved in the pathogenesis of $\mathrm{HD}$. They investigated the role of the $\mathrm{P}_{2} \mathrm{Y}_{2}$ receptor and spontaneous $\mathrm{Ca}^{2+}$ concentrations in embryonic stem cells in in vitro $\mathrm{HD}$ models and controls. In basal state $\mathrm{HD}$, there were higher intracellular $\mathrm{Ca}^{2+}$ levels than controls. Besides, there was elevated $\mathrm{P} 2 \mathrm{X} 7$ and $\mathrm{P}_{2} \mathrm{Y}_{2}$ receptor levels in the $\mathrm{HD}$ cell line compared with the controls (Glaser et al., 2020). Moreover, the cells from controls (WT cells) were responsive to the $\mathrm{P} 2 \mathrm{X} 7$ receptor agonist BzATP and the $\mathrm{P}_{2} \mathrm{Y}_{2}$ receptor agonist 2SUTP, while HD cells (expressing $\mathrm{mHTT}$ ) showed a decrease in the 2SUTP response, with impaired $\mathrm{P}_{2} \mathrm{Y}_{2}$ receptor activation (Glaser et al., 2020). The administration of ATP or 2SUTP in HD cells decreased the concentration of intracellular $\mathrm{Ca}^{2+}$ transients (Glaser et al., 2020). Therefore, these results indicate that $\mathrm{P} 2$ receptors contribute to the pathogenesis of $\mathrm{HD}$ (Figure 2) and provided the first evidence for the involvement of the $\mathrm{P}_{2} \mathrm{Y}_{2}$ receptor in this neurodegenerative disease.

Together, the above-mentioned studies shed new light on the mechanism underlying $\mathrm{HD}$, leading to the idea that pharmacological therapies based on $\mathrm{P} 2 \mathrm{X} 7$ and $\mathrm{P}_{2} \mathrm{Y}_{2}$ receptors should be better investigated for HD treatment.

\section{FOCUSING ON THE RELATIONSHIP BETWEEN NUCLEOTIDE AND NUCLEOSIDE METABOLISM AND HUNTINGTON'S DISEASE}

Reduced mitochondrial ATP levels and ATP/ADP ratios have been found in striatal cells containing mHTT (Seong et al., 2005). It is known that ATP depletion occurs in HD, so researchers have investigated nucleotide and nucleoside metabolism in this pathological condition. Researchers have demonstrated reduced mitochondrial ATP levels in cortical cells from an animal model of HD induced by 3-NPA, in cardiac tissue from two genetic models of HD (R6/2 and HdhQ150), and in a HEK293T cell line containing mHTT (Riepe et al., 1994; Toczek et al., 2016a, 2018). There was a decrease in the ATP/ADP ratio in cardiac tissue from R6/2 and HdhQ150 mice (Toczek et al., 2016a). There was also a reduction in ATP and AMP degradation in the HEK293T cell line containing mHTT (Toczek et al., 2018). Furthermore, studies in cardiac and cerebral tissue have shown no alteration in ADP levels in R6/2 and HdhQ150 mice. However, AMP levels were increased in R6/2 mice (Toczek et al., 2016a; Kao et al., 2017).

A genetic study of HD using different lines, including Tg51, zQ175, and R6/2, and a pharmacological model of HD induced by quinolinic acid and 3-NPA demonstrated a decrease in adenosine levels in the striatum of Tg51, zQ175, R6/2 lines, and HD animals induced by quinolinic acid and 3-NPA (Gianfriddo et al., 2003; Guitart et al., 2016; Jamwal and Kumar, 2016; Kao et al., 2017). Importantly, researchers have also found a decrease in adenosine levels in the cerebrospinal fluid of patients with HD compared with controls (Kao et al., 2017). Kao et al. (2017) observed that ATP was indirectly correlated with the number of CAG repeats and had a direct correlation with the age at onset of the disease while the adenosine/ATP ratio was negatively correlated with the disease duration of patients with HD (Kao et al., 2017).

Consistently, there was a decrease in ecto- $5^{\prime}$-nucleotidase (an enzyme that converts AMP to adenosine) activity in HEK 293T cell line containing $\mathrm{mHTT}$ and cardiac tissue from $\mathrm{R} 6 / 2$ mice (Toczek et al., 2016b, 2018), while there was an increase in ADA activity in cardiac tissue from R6/2 mice (Toczek et al., 2016b). Furthermore, in the striatum of rats treated with 3-NPA, there was a decrease in inosine and hypoxanthine levels compared with the control group (Jamwal and Kumar, 2016). On the other hand, Toczek et al. (2016a) found an increase in inosine, hypoxanthine, xanthine, uric acid, and uridine levels in cardiac tissue in R6/2 and HdhQ150 mice (Toczek et al., 2016a).

Genes involved in purine metabolism (Entpd2, Ampd3, Pnp, and $X d h$ ), adenosine metabolism (Ada), conversion of adenine nucleotides (adenylate kinase $1[A k 1]$ and inosine 


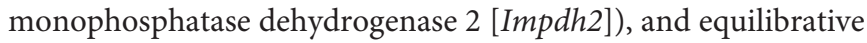
nucleoside transporter-like ENT1 and ENT2 were altered in cardiac tissue, striatum, and skeletal muscle of R6/2 mice of HD (Toczek et al., 2016a; Kao et al., 2017; Mielcarek et al., 2017). Moreover, in HD patients at the early stage of the disease, there was an upregulation of the gene that encodes ENT1 (Guitart et al., 2016). Finally, nitrobenzylthioinosine (NBTI), a selective inhibitor of ENT1, and dipyridamole (DPR), a non-specific inhibitor of ENT1 and ENT2, were intrastriatally perfused in R6/2 mice. Administration of NBTI alone increased adenosine levels 1-h post-treatment, whereas both NBTI and DPR administration increased adenosine levels 1$\mathrm{h}$ post-treatment, sustaining the effects up to $5 \mathrm{~h}$ post-treatment (Kao et al., 2017).

Regarding to studies in HD patients, it has been observed differences in the metabolism of nucleoside and its derivates. In plasma samples from HD patients, there was a significant increase in hypoxanthine and uridine levels, but there were not changes in uric acid levels compared with healthy subjects (Toczek et al., 2016a). Interestingly, hypoxanthine and uridine levels were directly correlated with HD duration and indirectly correlated with motor scores and chorea intensity (Toczek et al., 2016a). In contrast, Corey-Bloom et al. (2020) recently investigated uric acid levels in plasma and saliva samples from HD subjects and normal controls, as well as in post-mortem prefrontal cortical samples from HD subjects and controls. The authors surprisingly revealed that plasma and salivary uric acid levels were significantly lower in female pre-manifest HD and manifest HD subjects compared with normal controls, whereas salivary levels of uric acid were also significantly lower in male manifest HD subjects than controls. In male HD patients, plasma and salivary uric acid levels were negatively correlated with total functional capacity, while there were direct correlations with the total motor score. Female HD patients showed a direct correlation between plasma uric acid levels and total functional capacity, while salivary uric acid levels were significantly correlated with disease burden. Finally, in postmortem prefrontal cortical samples from HD subjects, there was a decrease in uric acid levels (Corey-Bloom et al., 2020).

Overall, these findings indicate that purinergic signaling plays an important role in HD by inhibiting the cascade of ATP hydrolysis, modulating the concentration of adenine nucleotides and nucleosides.

\section{CONCLUSION}

This review sheds light on the important regulatory role of purinergic signaling in HD pathophysiology. Notably, ATP, adenosine, and $\mathrm{A}_{2 A} \mathrm{R}$ are the main actors in HD. Although some results in animal models and HD patients are controversialdepending on the model tested, type of pharmacological treatment, and period of drug administration-pharmacological modulation of $\mathrm{A}_{2 A} \mathrm{R}$, through agonist and antagonist drugs, has shown a neuroprotective effect by attenuating the behavioral symptoms and improving neurochemical parameters during $\mathrm{HD}$ progression. Besides, $\mathrm{A}_{2 A} \mathrm{R}$ in the central and peripheral nervous system might be considered a powerful biomarker for HD progression and ought to be used in clinical practice. $\mathrm{A}_{2 A} \mathrm{R}$ heterodimerizes with several other G-protein coupled receptors involved in striatal dysfunction and degeneration in $\mathrm{HD}$; thus, $\mathrm{A}_{2 A} \mathrm{R}$ could be considered a target for the development of pharmacological therapies for HD patients.

Several small molecules acting as $\mathrm{A}_{2 A} \mathrm{R}$ antagonists have already been developed and tested in patients several neurological diseases, such as Parkinson's Disease. Although the efficacy of these agents in Parkinson's disease was not proved, the use of antagonists targeting $\mathrm{A}_{2 A} \mathrm{R}$ in cancer immunotherapy has been also investigated. The treatment with small molecules or $\mathrm{mAbs}$ aiming to block adenosine signaling, either by limiting its production or its binding to adenosine receptors, has yielded important tumor control in pre-clinical studies. Moreover, simultaneous blockade of adenosine production and receptor binding, achieved by an anti-CD73 mAb co-administered with an $\mathrm{A}_{2 A} \mathrm{R}$ antagonist, for example, have demonstrated synergy. Therefore, it is important to deepen the investigation of $A_{2 A} R$ as a target for the development of existing or new agents targeting this axis, along with further testing of combinatorial strategies, which may be relevant in the search for pharmacological therapies for HD patients. Moreover, the role of $\mathrm{A}_{1} \mathrm{R}$ and $\mathrm{P} 2$ receptors in $\mathrm{HD}$ pathogenesis needs to be reconsidered; there should be more specific investigation on these receptors, because they could provide a powerful contribution to understanding the mechanism underlying HD. In addition, nucleoside metabolism and the control of hypoxanthine, xanthine, and uric acid levels should also be deeply investigated, because these nucleosides might be important candidates for future drugs or biomarkers for HD. In summary, purinergic signaling represents a promising research area, and the main players, such as ATP, adenosine, and $A_{2 A} R$, as well as the respective coadjutants, such as $A_{1} R, P 2$ receptors, and other components of nucleotide and nucleoside metabolism, should be considered possible targets for drug development for HD treatment.

\section{AUTHOR CONTRIBUTIONS}

Both authors contributed for the conceptualization, performed the literature review, read and approved the submitted version. MW wrote the original draft of the manuscript. CB wrote and review and editing the final version of the manuscript.

\section{FUNDING}

This study was financed in part by the Coordenação de Aperfeiçoamento de Pessoal de Nível Superior-Brasil (CAPES)Finance Code 001, Conselho Nacional de Desenvolvimento Científico e Tecnológico (CNPq; 420695/2018-4 and 304450/2019-7), Fundação de Amparo à Pesquisa do Estado do Rio Grande do Sul (FAPERGS; 17/2551-0000977-0), and Instituto Nacional de Ciência e Tecnologia para Doenças Cerebrais, Excitotoxicidade e Neuroproteção. 


\section{REFERENCES}

Abbracchio, M. P., and Burnstock, G. (1994). Purinoceptors: are there families of P2X and P2Y purinoceptors? Pharmacol. Ther. 64, 445-475. doi: 10.1016/01637258(94)00048-4

Albin, R. L., Young, A. B., and Penney, J. B. (1989). The functional anatomy of basal ganglia disorders. Trends. Neurosci. 12, 366-375.

Alfinito, P. D., Wang, S. P., Manzino, L., Rijhsinghani, S., Zeevalk, G. D., and Sonsalla, P. K. (2003). Adenosinergic protection of dopaminergic and GABAergic neurons against mitochondrial inhibition through receptors located in the substantia nigra and striatum, respectively. J. Neurosci. 23, 10982-10987. doi: 10.1523/JNEUROSCI.23-34-10982-2003

Baig, S. S., Strong, M., and Quarrell, O. W. (2016). The global prevalence of Huntington's disease: a systematic review and discussion. Neurodegener. Dis. Manag. 6, 331-343. doi: 10.2217/nmt-2016-0008

Bailus, B., Zhang, N., and Ellerby, L. M. (2017). "Using genome engineering to understand huntington's disease," in Genome Editing in Neurosciences, eds R. Jaenisch, F. Zhang, and F. Gage (Brlin: Springer), 87-101. doi: 10.1007/978-3319-60192-2_9

Bates, G. P., Dorsey, R., Gusella, J. F., Hayden, M. R., Kay, C., Leavitt, B. R., et al. (2015). Huntington disease. Nat. Rev. Dis. Primers. 1:15005. doi: 10.1038/nrdp. 2015.5

Bauer, A., Zilles, K., Matusch, A., Holzmann, C., Riess, O., and Von Hörsten, S. (2005). Regional and subtype selective changes of neurotransmitter receptor density in a rat transgenic for the Huntington's disease mutation. J. Neurochem. 94, 639-650. doi: 10.1111/j.1447.4159.2005.03169.x

Benn, C. L., Slow, E. J., Farrell, L. A., Graham, R., Deng, Y., Hayden, M. R., et al. (2007). Glutamate receptor abnormalities in the YAC128 transgenic mouse model of huntington's disease. Neuroscience 147, 354-372. doi: 10.1016/ j.neuroscience.2007.03.010

Blum, D., Chern, Y., Domenici, M. R., Buée, L., Lin, C. Y., Rea, W., et al. (2018). The role of adenosine tone and adenosine receptors in huntington's disease. J. Caffeine. Adenosine. Res. 8, 43-58. doi: 10.1089/caff.2018.0006

Blum, D., Gall, D., Galas, M. C., d'Alcantara, P., Bantubungi, K., and Schiffmann, S. N. (2002). The adenosine Al receptor agonist adenosine amine congener exerts a neuroprotective effect against the development of striatal lesions and motor impairments in the 3-nitropropionic acid model of neurotoxicity. J. Neurosci. 22, 9122-9133. doi: 10.1523/JNEUROSCI.22.20.09122.2002

Blumenstock, S., and Dudanova, I. (2020). Cortical and striatal circuits in huntington's disease. Front. Neurosci. 14:82. doi: 10.3389/fnins.2020.00082

Bonan, C. D. (2012). Ectonucleotidases and nucleotide/nucleoside transporters as pharmacological targets for neurological disorders. CNS. Neurol. Disord. Drug. Targets. 11, 739-750. doi: 10.2174/187152712803 581092

Borea, P. A., Gessi, S., Merighi, S., Vincenzi, F., and Varani, K. (2018). Pharmacology of adenosine receptors: the state of the art. Physiol. Rev. 98, 1591-1625. doi: 10.1152/physrev.00049.2017

Bortolatto, C. F., Reis, A. S., Pinz, M. P., Voss, G. T., Oliveira, R. L., Vogt, A. G., et al. (2017). Selective A2A receptor antagonist SCH 58261 modulates striatal oxidative stress and alleviates toxicity induced by 3-Nitropropionic acid in male Wistar rats. Metab. Brain. Dis. 32, 1919-1927. doi: 10.1007/s11011-017-0086- 1

Burnstock, G. (1972). Purinergic nerves. Pharmacol. Rev. 24, 509-581.

Burnstock, G. (1980). Purinergic nerves and receptors. Prog. Biochem. Pharmacol. $16,141-154$.

Burnstock, G. (2008). Purinergic signalling and disorders of the central nervous system. Nat. Rev. Drug. Discov. 7, 575-590. doi: 10.1038/nrd2605

Burnstock, G. (2011). Adenosine and ATP receptors in the brain. Curr. Top. Med. Chem. 11, 973-1011. doi: 10.2174/156802611795347627

Burnstock, G. (2015). Purinergic signalling in neuroregeneration. Neural. Regn. Res. 10:1919. doi: 10.4103/1673-5374.165300

Burnstock, G. (2018). Purine and purinergic receptors. Brain. Neurosci. Adv. 2:2398212818817494. doi: 10.1177/2398212818817494

Capiluppi, E., Romano, L., Rebora, P., Nanetti, L., Castaldo, A., Gellera, C., et al. (2020). Late-onset huntington's disease with 40-42 CAG expansion. Neurol. Sci. 41, 869-876. doi: 10.1007/s10072-019-04177-8

Carmo, C., Naia, L., Lopes, C., and Rego, A. C. (2018). Mitochondrial dysfunction in huntington's disease. Adv. Exp. Med. Biol. 1049, 59-83. doi: 10.1007/978-3319-71779-1_3
Cha, J. H. J., Frey, A. S., Alsdorf, S. A., Kerner, J. A., Kosinski, C. M., Mangiarini, L., et al. (1999). Altered neurotransmitter receptor expression in transgenic mouse models of Huntington's disease. Philos. Trans. R. Soc. B Biol. Sci. 354, 981-989. doi: 10.1098/rstb.1999.0449

Chan, E. Y. W., Luthi-Carter, R., Strand, A., Solano, S. M., Hanson, S. A., DeJohn, M. M., et al. (2002). Increased huntingtin protein length reduces the number of polyglutamine-induced gene expression changes in mouse models of Huntington's disease. Hum. Mol. Genet. 11, 1939-1951. doi: 10.1093/hmg/ 11.17.1939

Cheffer, A., Castillo, A. R. G., Corrêa-Velloso, J., Gonçalves, M. C. B., Naaldijk, Y., Nascimento, I. C., et al. (2018). Purinergic system in psychiatric diseases. Mol. Psychiatry. 23, 94-106. doi: 10.1038/mp.2017.188

Chen, J. F., and Chern, Y. (2011). Impacts of methylxanthines and adenosine receptors on neurodegeneration: human and experimental studies. Handb. Exp. Pharmacol. 200, 267-310. doi: 10.1007/978-3-642-13443-2_10

Chiang, M. C., Chen, H. M., Lai, H. L., Chen, H. W., Chou, S. Y., Chen, C. M., et al. (2009). The A2A adenosine receptor rescues the urea cycle deficiency of Huntington's disease by enhancing the activity of the ubiquitin-proteasome system. Hum. Mol. Genet. 18, 2929-2942. doi: 10.1093/hmg/ddp230

Chou, S. Y., Lee, Y. C., Chen, H. M., Chiang, M. C., Lai, H. L., Chang, H. H., et al. (2005). CGS21680 attenuates symptoms of huntington's disease in a transgenic mouse model. J. Neurochem. 93, 310-320. doi: 10.1111/j.1471.4159.2005.03 029.x

Cieslak, M., Roszek, K., and Wujak, M. (2019). Purinergic implication in amyotrophic lateral sclerosis- from pathological mechanisms to therapeutic perspectives. Purinergic. Signal 15, 1-15. doi: 10.1007/s11302-018-9633-4

Ciruela, F. (2020). Special issue: G protein-coupled adenosine receptors: molecular aspects and beyond. Int. J. Mol. Sci. 21:1997. doi: 10.3390/ijms21061997

Ciruela, F., Fernández-Dueñas, V., and Jacobson, K. A. (2015). Lighting up $\mathrm{G}$ protein-coupled purinergic receptors with engineered fluorescent ligands. Neuropharmacology 98, 58-67. doi: 10.1016/j.neuropharm.2015.04.001

Coppen, E. M., and Roos, R. A. C. (2017). Current pharmacological approaches to reduce chorea in huntington's disease. Drugs. 77, 29-46. doi: 10.1007/s40265016-0670-4

Corey-Bloom, J., Haque, A., Aboufadel, S., Snell, C., Fischer, R. S., Granger, S. W., et al. (2020). Uric acid as a potential peripheral biomarker for disease features in huntington's patients. Front. Neurosci. 14:73. doi: 10.3389/fnins.2020.00073

Croce, K. R., and Yamamoto, A. A. (2019). A role for autophagy in huntington's disease. Neurobiol. Dis. 122, 16-22. doi: 10.1016/j.nbd.2018.08.010

Cunha, R. A. (2005). Neuroprotection by adenosine in the brain: From A(1) receptor activation to A(2A) receptor blockade. Purinergic. Signal 1, 111-134. doi: 10.1007/s11302-005-0649-1

Cybulska, K., Perk, L., Booij, J., Laverman, P., and Rijpkema, M. (2020). Huntington's disease: a review of the known pet imaging biomarkers and targeting radiotracers. Molecules 25:482.

Dhaenens, C. M., Burnouf, S., Simonin, C., Brussel, E., Van Duhamel, A., Defebvre, L., et al. (2009). A genetic variation in the ADORA2A gene modifies age at onset in huntington's disease. Neurobiol. Dis. 35, 474-476. doi: 10.1016/j.nbd.2009.06. 009

Díaz-Hernández, M., Díez-Zaera, M., Sánchez-Nogueiro, J., Gómez-Villafuertes, R., Canals, J. M., Alberch, J., et al. (2009). Altered P2X7-receptor level and function in mouse models of huntington's disease and therapeutic efficacy of antagonist administration. FASEB. J. 23, 1893-1906. doi: 10.1096/fj.08.122275

Domenici, M. R., Chiodi, V., Averna, M., Armida, M., Pèzzola, A., Pepponi, R., et al. (2018). Neuronal adenosine A2Areceptor overexpression is neuroprotective towards 3-nitropropionic acid-induced striatal toxicity: a rat model of huntington's disease. Purinergic. Signal 14, 235-243. doi: 10.1007/s11302.0180609-4

Domenici, M. R., Scattoni, M. L., Martire, A., Lastoria, G., Potenza, R. L., Borioni, A., et al. (2007). Behavioral and electrophysiological effects of the adenosine A2A receptor antagonist SCH 58261 in R6/2 Huntington's disease mice. Neurobiol. Dis. 28, 197-205. doi: 10.1016/j.nbd.2007.07.009

Dufour, B. D., and McBride, J. L. (2019). Normalizing glucocorticoid levels attenuates metabolic and neuropathological symptoms in the R6/2 mouse model of Huntington's disease. Neurobiol. Dis. 121, 214-229. doi: 10.1016/j.nbd. 2018.09.025

Ferrante, A., Martire, A., Armida, M., Chiodi, V., Pézzola, A., Potenza, R. L., et al. (2010). Influence of CGS 21680, a selective adenosine A2A receptor agonist, on 
NMDA receptor function and expression in the brain of Huntington's disease mice. Brain. Res. 1323, 184-191. doi: 10.1016/jbrainres.2010.01.080

Ferrante, A., Martire, A., Pepponi, R., Varani, K., Vincenzi, F., Ferraro, L., et al. (2014). Expression, pharmacology and functional activity of adenosine A1 receptors in genetic models of Huntington's disease. Neurobiol. Dis. 71, 193 204. doi: 10.1016/j.nbd.2014.08.013

Ferré, S., Ciruela, F., Quiroz, C., Luján, R., Popoli, P., Cunha, R. A., et al. (2007). Adenosine receptor heteromers and their integrative role in striatal function. Scientific. World. J. 7, 74-85. doi: 10.1100/tsw.2007.211

Fink, J. S., Kalda, A., Ryu, H., Stack, E. C., Schwarzschild, M. A., Chen, J. F., et al. (2004). Genetic and pharmacological inactivation of the adenosine A2A receptor attenuates 3-nitropropionic acid-induced striatal damage. J. Neurochem. 88, 538-544. doi: 10.1046/j.1471.4159.2003.02145.x

Fredholm, B. B., Ijzerman, A. P., Jacobson, K. A., Klotz, K. N., and Linden, J. (2001). International Union of Pharmacology. XXV. nomenclature and classification of adenosine receptors. Pharmacol. Rev. 53, 527-552.

Fuxe, K., Ferré, S., Genedani, S., Franco, R., and Agnati, L. F. (2007). Adenosine receptor-dopamine receptor interactions in the basal ganglia and their relevance for brain function. Physiol. Behav. 92, 210-217. doi: 10.1016/j. physbeh.2007.05.034

Gianfriddo, M., Corsi, C., Melani, A., Pèzzola, A., Reggio, R., Popoli, P., et al. (2003). Adenosine A2A antagonism increases striatal glutamate outflow in the quinolinic acid rat model of Huntington's disease. Brain. Res. 979, 225-229. doi: 10.1016/s0006-8993(03)02942-1

Glaser, T., Hiromi, S., Ribeiro, D. E., Martins, P. P. L., Beco, R. P., Kosinski, M., et al. (2020). ATP and spontaneous calcium oscillations control neural stem cell fate determination in Huntington's disease: a novel approach for cell clock research. Mol. Psychiatry. doi: 10.1038/s41380-020-0717-5 [Epub ahead of print].

Glass, M., Dragunow, M., and Faull, R. L. M. (2000). The pattern of neurodegeneration in Huntington's disease: a comparative study of cannabinoid, dopamine, adenosine and $\mathrm{GABA}(\mathrm{A})$ receptor alterations in the human basal ganglia in Huntington's disease. Neuroscience 97, 505-519. doi: 10.1016/s0306-4522(00)00008-7

Graybiel, A. M. (2000). The basal ganglia. Curr. Biol. 10, R509-R511. doi: 10.1016/ s0960-9822(00)00593-5

Guitart, X., Bonaventura, J., Rea, W., Orrú, M., Cellai, L., Dettori, I., et al. (2016). Equilibrative nucleoside transporter ENT1 as a biomarker of Huntington disease. Neurobiol Dis. 96, 47-53. doi: 10.1016/j.nbd.2016.08.013

Gundlfinger, A., Bischofberger, J., Johenning, F. W., Torvinen, M., Schmitz, D., and Breustedt, J. (2007). Adenosine modulates transmission at the hippocampal mossy fiber synapse via direct inhibition of presynaptic calcium channels. J. Physiol. 582, 263-277. doi: 10.1113/jphysiol.2007.132618

Illarioshkin, S. N., Klyushnikov, S. A., Vigont, V. A., Seliverston, Y. A., and Kaznacheyeva, E. V. (2018). Molecular pathogenesis in Huntington's Disease. Biochemistry (Mosc.) 83, 1030-1039. doi: 10.1134/S0006297918090043

Jamwal, S., and Kumar, P. (2016). Spermidine ameliorates 3-nitropropionic acid (3-NP)- induced striatal toxicity: possible role of oxidative stress, neuroinflammation, and neurotransmitters. Physiol. Behav. 155, 180-187. doi: 10.1016/j.physbeh.2015.12.015

Jamwal, S., and Kumar, P. (2019). Insight into the emerging role of striatal neurotransmitters in the pathophysiology of Parkinson's disease and Huntington's disease: a review. Curr. Neuropharmacol. 17, 165-175. doi: 10. 2174/1570159X6666180302115032

Jamwal, S., Singh, S., Kaur, N., and Kumar, P. (2015). Protective effect of spermidine against excitotoxic neuronal death induced by quinolinic acid in rats: possible neurotransmitters and neuroinflammatory mechanisms. Neurotox. Res. 28, 171-184. doi: 10.1007/s12640-015-9535-y

Jodeiri Farshbaf, M., and Kiani-Esfahani, A. (2018). Succinate dehydrogenase: prospect for neurodegenerative diseases. Mitochondrion 42, 77-83. doi: 10. 1016/j.mito.2017.12.002

Johri, A., Chandra, A., and Beal, M. F. (2013). PGC-1 $\alpha$, mitochondrial dysfunction, and Huntington's disease. Free. Radic. Biol. Med. 62, 37-46. doi: 10.1016/j. freeradbiomed.2013.04.016

Kao, Y. H., Lin, M. S., Chen, C. M., Wu, Y. R., Chen, H. M., Lai, H. L., et al. (2017). Targeting ENT1 and adenosine tone for the treatment of Huntington's disease. Hum. Mol. Genet. 26, 467-478. doi: 10.1093/hmg/ddw 402
Kish, S. J., Shannak, K., and Hornykiewicz, O. (1987). Elevated serotonin and reduced dopamine in subregionally divided Huntington's disease striatum. Ann. Neurol. 22, 386-389. doi: 10.1002/ana.410220318

Koch, E. T., and Raymond, L. A. (2019). Dysfunctional striatal dopamine signaling in Huntington's disease. J. Neurosci. Res. 97, 1636-1654. doi: 10.1002/jnr.24495

Latini, S., and Pedata, F. (2001). Adenosine in the central nervous system: release mechanisms and extracellular concentrations. J. Neurochem. 79, 463-484. doi: 10.1046/j.1471-4159.2001.00607.x

León-Navarro, D. A., Albasanz, J. L., and Martín, M. (2018). Functional cross-talk between adenosine and metabotropic glutamate receptors. Curr. Neuropharmacol. 17, 422-437. doi: 10.2174/1570159X16666180416093717

Li, W., Silva, H. B., Real, J., Wang, Y. M., Rial, D., Li, P., et al. (2015). Inactivation of adenosine A2A receptors reverses working memory deficits at early stages of Huntington's disease models. Neurobiol. Dis. 79, 70-80. doi: 10.1016/j.nbd. 2015.03.030

Liot, G., Valette, J., Pépin, J., Flament, J., and Brouillet, E. (2017). Energy defects in Huntington's disease: Why "in vivo" evidence matters. Biochem. Biophys. Res. Commun. 483, 1084-1095. doi: 10.1016/j.bbrc.2016.09.065

Maglione, V., Cannella, M., Martino, T., De Blasi, A., Frati, L., and Squitieri, F. (2006). The platelet maximum number of A2A-receptor binding sites (Bmax) linearly correlates with age at onset and CAG repeat expansion in Huntington's disease patients with predominant chorea. Neurosci. Lett. 393, 27-30. doi: 10. 1016/j.neulet.2005.09.037

Maglione, V., Giallonardo, P., Cannella, M., Martino, T., Frati, L., and Squitieri, F. (2005). Adenosine A2A receptor dysfunction correlates with age at onset anticipation in blood platelets of subjects with Huntington's disease. Am. J. Med. Genet. Neuropsychiatr. Genet. 139 B, 101-105. doi: 10.1002/ajmg.b.30223

Martinez-Mir, M. I., Probst, A., and Palacios, J. M. (1991). Adenosine A2 receptors: selective localization in the human basal ganglia and alterations with disease. Neuroscience 42, 697-706. doi: 10.1016/0306-4522(91)90038-p

Martire, A., Calamandrei, G., Felici, F., Scattoni, M. L., Lastoria, G., Domenici, M. R., et al. (2007). Opposite effects of the A2A receptor agonist CGS21680 in the striatum of Huntington's disease versus wild-type mice. Neurosci. Lett. 417, 78-83. doi: 10.1016/j.neulet.2007.02.034

Martire, A., Pepponi, R., Liguori, F., Volonté, C., and Popoli, P. (2021). P2X7 receptor agonist 2'(3')-O-(4-Benzoylbenzoyl)ATP differently modulates cell viability and coricostriatal synaptic transmission in experimental models of Huntington's disease. Front. Pharmacol. 19:633861. doi: 10.3389/fphar.2020. 633861

Matusch, A., Saft, C., Elmenhorst, D., Kraus, P. H., Gold, R., Hans-Peter, H., et al. (2014). Cross-sectional PET study of cerebral adenosine A1 receptors in premanifest and manifest Huntington's disease. Eur. J. Nucl. Med. Mol. Imaging. 41, 1210-1220. doi: 10.1007/s00259-014-2724-8

Mielcarek, M., Smolenski, R. T., and Isalan, M. (2017). Transcriptional signature of an altered purine metabolism in the skeletal muscle of a Huntington's disease mouse model. Front. Physio. 8:127. doi: 10.3389/fphys.2017.00127

Mievis, S., Blum, D., and Ledent, C. (2011). A2A receptor knockout worsens survival and motor behavior in a transgenic mouse model of Huntington's disease. Neurobiol. Dis. 41, 570-576. doi: 10.1016/j.nbd.2010.09.021

Minghetti, L., Greco, A., Potenza, R. L., Pezzola, A., Blum, D., Bantubungi, K., et al. (2007). Effects of the adenosine A2A receptor antagonist SCH 58621 on cyclooxygenase-2 expression, glial activation, and brain-derived neurotrophic factor availability in a rat model of striatal neurodegeneration. J. Neuropathol. Exp. Neurol. 66, 363-371. doi: 10.1097/nen.0b013e3180517477

Mishra, J., and Kumar, A. (2014). Improvement of mitochondrial NAD+/FAD+linked state- 3 respiration by caffeine attenuates quinolinic acid-induced motor impairment in rats: implications in Huntington's disease. Pharmacol. Rep. 66, 1148-1155. doi: 10.1016/j.pharep.2014.07.006

Ollà, I., Santos-Galindo, M., Elorza, A., and Lucas, J. J. (2020). P2X7 receptor upregulation in Huntington's disease brains. Front. Mol. Neurosci. 6:567430. doi: $10.3389 /$ fnmol.2020.567430

Petersén, A., and Weydt, P. (2019). The psychopharmacology of Huntington disease. Handb. Clin. Neurol. 165, 179-189.

Popoli, P., Pintor, A., Domenici, M. R., Frank, C., Tebano, M. T., Pezzola, A., et al. (2002). Blockade of striatal adenosine A2A receptor reduces, through a presynaptic mechanism, quinolinic acid-induced excitotoxicity: possible relevance to neuroprotective interventions in neurodegenerative diseases of the 
striatum. J. Neurosci. 22, 1967-1975. doi: 10.1523/JNEUROOSCI.22-05-01967. 2002

Potenza, R. L., Tebano, M. T., Martire, A., Domenici, M. R., Pepponi, R., Armida, M., et al. (2007). Adenosine A2A receptors modulate BDNF both in normal conditions and in experimental models of Huntington's disease. Purinergic. Signal. 3, 333-338. doi: 10.1007/s11302-007-9066-y

Puchałowicz, K., Tarnowski, M., Baranowska-Bosiacka, I., Chlubek, D., and Dziedziejko, V. (2014). P2X and P2Y receptors-role in the pathophysiology of the nervous system. Int. J. Mol. Sci. 15, 23672-23704. doi: 10.3390/ ijms 151223672

Rai, S. N., Singh, B. K., Rathore, A. S., Zahra, W., Keswani, C., Birla, H., et al. (2019). Quality control in Huntington's disease: a therapeutic target. Neurotox. Res. 36, 612-626. doi: 10.1007/s12640-019-00087-x

Ramaswamy, S., Mcbride, J. L., and Kordower, J. H. (2007). Animal models of Huntington's Disease. ILAR. J. 48, 356-373. doi: 10.1093/ilar.48.4.356

Ribeiro, F. F., Xapelli, S., Miranda-Lourenço, C., Tanqueiro, S. R., Fonseca-Gomes, J., Diógenes, M. J., et al. (2016). Purine nucleosides in neuroregeneration and neuroprotection. Neuropharmacology 104, 226-242. doi: 10.1016/neuropharm. 2015.11.006

Riepe, M., Ludolph, A., Seelig, M., Spencer, P. S., and Ludolph, A. C. (1994). Increase of ATP levels by glutamate antagonists is unrelated to neuroprotection. Neuroreport 5, 2130-2132. doi: 10.1097/00001756-199410270-00035

Rubinsztein, D. C. (2002). Lessons from animal models of Huntington's disease. Trends. Genet. 18, 202-209. doi: 10.1016/s0168-9525(01)02625-7

Scattoni, M. L., Valanzano, A., Pezzola, A., March, Z., De Fusco, F. R., Popoli, P., et al. (2007). Adenosine A2A receptor blockade before striatal excitotoxic lesions prevents long term behavioral disturbances in the quinolinic rat model of Huntington's disease. Behav. Brain. Res. 176, 216-221. doi: 10.1016/j.bbr. 2006.10.004

Seong, I. S., Ivanova, E., Lee, J. M., Choo, Y. S., Fossale, E., Anderson, M., et al. (2005). HD CAG repeat implicates a dominant property of huntingtin in mitochondrial energy metabolism. Hum. Mol. Genet. 14, 2871-2880. doi: 10.1093/hmg/ddi319

Sheth, S., Brito, R., Mukherjea, D., Rybak, L. P., and Ramkumar, V. (2014). Adenosine receptors: expression, function and regulation. Int. J. Mol. Sci. 15, 2024-2052. doi: 10.3390/ijms15022024

Shoulson, I., and Young, A. B. (2011). Milestones in huntington disease. Mov. Disord. 26, 1127-1133. doi: 10.1002/mds.23685

Simonin, C., Duru, C., Salleron, J., Hincker, P., Charles, P., Delval, A., et al. (2013). Association between caffeine intake and age at onset in Huntington's disease. Neurobiol. Dis. 58, 179-182. doi: 10.1016/j.nbd.2013.0 5.013

Smith-Dijak, A. I., Sepers, M. D., and Raymond, L. A. (2019). Alterations in synaptic functions and plasticity in Huntington disease. J. Neurochem. 150, 346-365. doi: 10.1111/jnc. 14723

Spokes, E. G. S. (1980). Neurochemical alterations in Huntington's chorea: a study of post-mortem brain tissue. Brain 103, 179-210. doi: 10.1093/brain/103.1.179

Stahl, C. M., and Feigin, A. (2020). Medical, surgical, and genetic treatment of Huntington disease. Neurol. Clin. 38, 367-378. doi: 10.1016/j.ncl.2020. 01.010

Stockwell, J., Jakova, E., and Cayabyab, F. S. (2017). Adenosine A1 and A2A receptors in the brain: current research and their role in neurodegeneration. Molecules 22, 1-18. doi: 10.3390/molecules22040676

Taherzadeh-Fard, E., Saft, C., Wieczorek, S., Epplen, J. T., and Arning, L. (2010). Age at onset in Huntington's disease: replication study on the associations of ADORA2A, HAP1 and OGG1. Neurogenetics 11, 435-439. doi: 10.1007/ s10048-010-0248-3
Tarditi, A., Camurri, A., Varani, K., Borea, P. A., Woodman, B., Bates, G., et al. (2006). Early and transient alteration of adenosine A2A receptor signaling in a mouse model of Huntington disease. Neurobiol. Dis. 23, 44-53. doi: 10.1016/j. nbd.2006.01.014

The Huntington's Disease Collaborative Research Group (1993). A novel gene containing a trinucleotide repeat that is expanded and unstable on Huntington's disease chromosomes. Cell 72, 971-983. doi: 10.1016/0092-8674(93)90585-e

Toczek, M., Kutryb-Zajac, B., Zukowska, P., Slominska, E. M., Isalan, M., Mielcarek, M., et al. (2016b). Changes in cardiac nucleotide metabolism in Huntington's disease. Nucleosides. Nucleotides. Nucleic. Acids. 35, 707-712. doi: 10.1080/1527770.2016.1154969

Toczek, M., Pierzynowska, K., Kutryb-Zajac, B., Gaffke, L., Slominska, E. M., Wegrzyn, G., et al. (2018). Characterization of adenine nucleotide metabolism in the cellular model of Huntington's disease. Nucleosides. Nucleotides. Nucleic. Acids. 37, 630-638. doi: 10.1080/15257770.2018.1481508

Toczek, M., Zielonka, M., Zukowska, P., Marcnkow ski, J. T., Slominska, E., Isalan, M., et al. (2016a). An impaired metabolism of nucleotides underpins a novel mechanism of cardiac remodeling leading to Huntington's disease related cardiomyopathy. Biochim. Biophys. Acta 1862, 2147-2157. doi: 10.1016/ j.bbadis.2016.08.019

Varani, K., Abbracchio, M. P., Cannella, M., Cislaghi, G., Giallonardo, P., Mariotti, C., et al. (2003). Aberrant A2A receptor function in peripheral blood cells in Huntington's disease. FASEB. J. 17, 2148-2150. doi: 10.1002/ajmg.b.30223

Villar-Menéndez, I., Blanch, M., Tyebji, S., Pereira-Veiga, T., Albasanz, J. L., Martín, M., et al. (2013). Increased 5-methylcytosine and decreased 5hydroxymethylcytosine levels are associated with reduced striatal A2AR levels in Huntington's disease. NeuroMolecular. Med. 15, 295-309. doi: 10.1007/ s12017-013-8219-0

Von Lubitz, D. K., Paul, I. A., Ji, X. D., Carter, M., and Jacobson, K. A. (1994). Chronic adenosine Al receptor agonist and antagonist: effect on receptor density and N-methyl-D-aspartate induced seizures in mice. Eur. J. Pharmacol. 253, 95-99. doi: 10.1016/0014-2999(94)90762-5

Whitehouse, P. J., Trifiletti, R. R., Jones, B. E., Folstein, S., Price, D. L., Snyder, S. H., et al. (1985). Neurotransmitter receptor alterations in Huntington's disease: Autoradiographic and homogenate studies with special reference to benzodiazepine receptor complexes. Ann. Neurol. 18, 202-210. doi: 10.1002/ ana.410180207

Yegutkin, G. G. (2008). Nucleotide- and nucleoside- converting ectoenzymes: Important modulators of purinergic signalling cascade. Biochem. Biophys. Acta. 1783, 673-694. doi: 10.1016/j.bbamcr.2008.01.024

Yoon, K. W., and Rothman, S. M. (1991). Adenosine inhibits excitatory but not inhibitory synaptic transmission in the hippocampus. J. Neurosci. 11, 13751380. doi: 10.1523/JNEUROSCI.11-05-01375-1991

Zimmermann, H. (2021). Ectonucleoside triphosphate diphosphohydrolases and ecto- 5 '-nucleotidase in purinergic signaling: how the field developed and where we are now. Purinergic Signal. 17, 117-125. doi: 10.1007/s11302-020-09755-6

Conflict of Interest: The authors declare that the research was conducted in the absence of any commercial or financial relationships that could be construed as a potential conflict of interest.

Copyright (๑) 2021 Wiprich and Bonan. This is an open-access article distributed under the terms of the Creative Commons Attribution License (CC BY). The use, distribution or reproduction in other forums is permitted, provided the original author(s) and the copyright owner(s) are credited and that the original publication in this journal is cited, in accordance with accepted academic practice. No use, distribution or reproduction is permitted which does not comply with these terms. 